\title{
Influence of Organic Additive Benzene Sulfonic Acid on the Magnetic Behavior of Electrodeposited COMNP Thin Film Alloys
}

\author{
M.RM. Krishnappa, K.V. Kannan Nithin
}

\begin{abstract}
CoMnP alloy films were synthesized by Electrodeposition Technique. The Electrochemical deposition technique is especially interesting due to its low cost and high quality of deposit. Thin Magnetic films are extensively used in various electronic devices including high density recording media and micro electromechanical systems (MEMS). Electrodeposition being cost effective, in the present work cobalt based magnetic films was deposited electrochemically and characteristics features of the deposited film were studied. Effect of organic additives Benzene sulfonic acid in the presence of the sodium hypophosphite was studied. Structural and magnetic properties were investigated and reported. The hysteresis loops of the CoMnP alloy films were measured and studied. The result shows that organic additive Benzene sulfonic acid has altered the magnetic properties of the films. Among the different compositions, CoMnP compound exhibit good hard magnetic properties, Under the best condition involving addition of $0.2 \mathrm{M}$ of NaH2PO2 and $4 \mathrm{gL}-1$ of Benzene Sulfonic Acid at a current density of $7 \mathrm{~mA}-\mathrm{cm}-2$ and time of deposition 60 minutes, the thickness of the film was found to be 3.5 micrometer with coercivity 1410 Oe and remanent 0.12 emu. The reason for the change in magnetic properties and structural characteristics because of the additive were discussed.
\end{abstract}

Keywords-CoMnP thin films, organic additive Benzene sulfonic acid, Magnetic properties.

\section{INTRODUCTION}

Different actuation mechanisms for microactuators include electrostatic [1], Piezoelectric[2], thermopneumatic[3], bimetallic[4], electromagnetic[5], electrochemical[6] and shape memory alloys [7]. At present hard and soft magnetic material gains increasing interest in micro electro mechanical systems and micro optical electrochemical system devices, for example microaculators and sensors. In particular hard magnetic materials are advantageous to bidirectional actuation, which is needed in bidirectional actuation. The importance of electrodeposition as a fabrication technology in the electronic industry is large and growing. [8]. Development of microelectromechanical system [ MEMS ] requires hard magnetic films with both high coercivity and remanence [9]. Electrodeposited thin

Revised Manuscript Received on July 08, 2019.

M.RM. Krishnappa Department of Physics Sri Ramakrishna Engineering College, Coimbatore, India. srisaitechnologymadurai@gmail.com

K.V. Kannan Nithin Department of Physics Kathir College of Engineering, Coimbatore, India magnetic films are important in computer read/ write heads and MEMS because of their fiexibility, capability, quality and low cost. With the current trend towards miniaturization, high performance packaging, cost-competitiveness and electro deposition has become the dominant manufacturing technology in many new applications and remains firmly established in others. For example in micro electro mechanical system ( MEMS ) devices, data storage media, magnetic recording head and reading heads [8]. In addition to the above, Electrodeposition has been recognized as a preparation method characterized by remarkable degree of reproducibility. The electro deposition technique is especially interesting due its costeffectiveness, quality deposits and easy maintenance. As CoMnP ternary alloy films are having hard magnetic properties various studies have been carried out to develop these thin magnetic films. Electro-deposition provides an easy way to produce these thin films with high quality[10]. As of now, various Co-based permanent- magnet materials have been electrodeposited because of the crystalline structure of cobalt is highly anisotropic. Numerous studies have been carried out to investigate binary and ternary Co based iron group magnetic films[11]. They mostly focused on the mechanism of anomalous codeposition, effect of plating, the effect of various additives and the corrosion properties. To our knowledge, there have been a few detailed studies on Co based magnetic films prepared using electro deposition [12]. The purpose of the present work was to study the influence of bath parameters (current density, $\mathrm{pH}$, and time duration of deposition) mainly on the magnetic properties of electro deposited CoMnP thin films. CoMnP films were characterized using Vibrating sample Magnetometer (VSM), energy dispersive X-Ray Spectroscopy (EDS), X-Ray diffractometer (XRD) and the influence of the bath parameters on the film structure, composition, and magnetic properties were discussed. The influence of the organic additive Benzene Sulfonic Acid on the magnetic properties was also studied.

\section{EXPERIMENTAL DETAILS}

All the CoMnP films were electrodeposited at constant $\mathrm{pH}$ value 3.00.The CoMnP films were electro deposited on Copper substrates of size: breath; $20 \mathrm{~mm} \mathrm{X} \mathrm{Length} \mathrm{;120} \mathrm{mm}$ $\mathrm{X}$ Thickness $0.1 \mathrm{~mm}$. Pure Cobalt of the same size was used as anode. Current for electrodeposition was passed from a regulated direct current (DC) unit. Analytical reagent grade chemicals were used to prepare baths Solution. Each and every 
substrate was buffed for removing scratches in a mechanical polishing wheel using a buffing cloth coated with aluminium oxide abrasive. Buffed substrates were degreased using acetone. Before electrodeposition these substrates were electrocleaned in an alkaline electrocleaning bath solution. The bath solution contains sodium hydroxide: $7.0 \mathrm{~g} \mathrm{l}^{-1}$; sodium carbonate: $20.0 \mathrm{~g} \mathrm{l}^{-1}$; trisodium phosphate: $9.0 \mathrm{~g} \mathrm{l}^{-1}$ and sodium metasilicate: $24.0 \mathrm{~g} \mathrm{l}^{-1}$. The bath solution was operated at room temperature and current density applied was $3.0 \mathrm{~A} \mathrm{dm}^{-2}$. After electrocleaning the substrates were rinsed with distilled water. Electrodeposition process was carried out on the cleaned substrates using different current density and time of deposition. CoMnP thin films were electrodeposited in the chloride baths. Table I lists the plating composition investigated.

Table I

PLATING SOLUTION COMPOSITION.

\begin{tabular}{|l|l|}
\hline & \\
Electrochemical bath & Plating solution composition \\
\hline & $\mathrm{CoCl}_{2}: 0.42 \mathrm{M} ; \mathrm{CoSo}_{4}: 0.053 \mathrm{M}^{\prime} \mathrm{MnCl}_{2}:$ \\
& $0.4 \mathrm{M} ; \mathrm{NH}_{4} \mathrm{Cl}: 1.8 \mathrm{M}$ and $\mathrm{NaH}_{2} \mathrm{Po}_{2}: 0.2$ \\
& $\mathrm{M}$ \\
\hline & Sample A composition plus Benzene \\
Sample A1 & Sulfonic Acid $2 \mathrm{gL}^{-1}$ \\
\hline & Sample A composition plus Benzene \\
Sample A2 & Sulfonic Acid $4 \mathrm{gL}^{-1}$ \\
\hline & $\mathrm{CoCl}_{2}: 0.42 \mathrm{M} ; \mathrm{CoSo}_{4}: 0.053 \mathrm{M} ; \mathrm{MnCl}_{2}:$ \\
Sample B & $0.4 \mathrm{M} ; \mathrm{NH}_{4} \mathrm{Cl}: 1.8 \mathrm{M}$ and $\mathrm{NaH}_{2} \mathrm{Po}_{2}: 0.4 \mathrm{M}$ \\
\hline & Sample B composition plus Benzene \\
Sample B1 & Sulfonic Acid $2 \mathrm{gL}^{-1}$ \\
\hline & Sample B composition plus Benzene \\
Sample B2 & Sulfonic Acid $4 \mathrm{gL}^{-1}$ \\
\hline
\end{tabular}

igital micro meter was used to meas ure the thick ness of the deposits. Vibrating sample magnetometer was used to study the Magnetic properties of deposited films. Scanning electron microscopy (SEM) and X-ray diffractometry (XRD) were used to study the morphology and structure of these films respectively. From XRD data, the film stresses were calculated using the crystallite size of the deposited CoMnP magnetic thin films. Percentage of elements such as Cobalt, Manganese and phosphorous present in the deposits were obtained.

\section{RESULTS AND DISCUSSIONS}

Elements present in the magnetic film were analyzed by energy dispersive X-ray spectroscopy (EDS) and the results are listed in the Table 2.

Table II

Magnetic Thin Film Composition.

\begin{tabular}{|l|l|l|l|}
\hline \multirow{2}{*}{ Bath } & \multicolumn{3}{|l|}{ Magnetic Thin Film composition ( at \% ) } \\
\cline { 2 - 4 } & Co & Mn & P \\
\hline Sample A & $96.34 \%$ & $1.72 \%$ & $1.04 \%$ \\
\hline Sample A1 & $97.48 \%$ & $1.15 \%$ & $1.37 \%$ \\
\hline Sample A2 & $96.98 \%$ & $1.20 \%$ & $1.92 \%$ \\
\hline Sample B & $97.94 \%$ & $1.52 \%$ & $0.64 \%$ \\
\hline Sample B1 & $97.49 \%$ & $1.40 \%$ & $1.11 \%$ \\
\hline Sample B2 & $97.01 \%$ & $1.22 \%$ & $1.77 \%$ \\
\hline
\end{tabular}

It was observed that all the magnetic films obtained from various baths had less than $1.92 \%$ phosphorous. Even with this low phosphorous content the films showed high magnetic properties. The improved crystalline structure of CoMnP magnetic thin films was due to the addition of Benzene Sulfonic Acid in the various baths. Electro deposited CoMnP thin films were subjected to XRD studies. $\mathrm{X}$-ray Diffraction patterns of different CoMnP thin magnetic film deposits produced from different current densities 3, 5 and $7 \mathrm{~mA} \mathrm{~cm}^{-1}$ for various time of depositions 15, 30 and 60 minutes were obtained. The XRD pattern were presented in the Fig. 1 and Fig. 2.

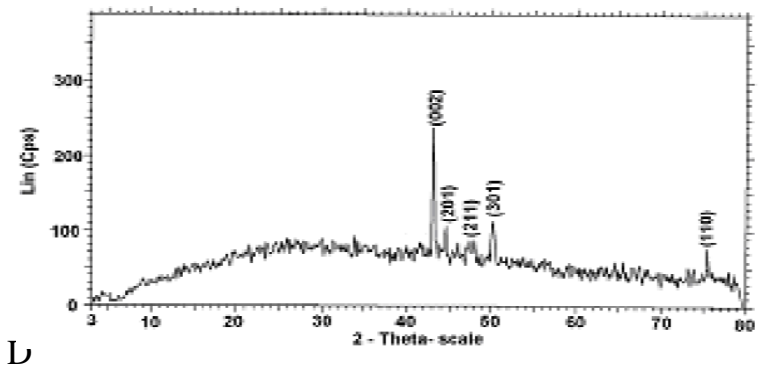

Fig. 1.. XRD pattern of Electrodeposited CoMnP film; for sample A. Current Density $3 \mathrm{~mA} / \mathrm{cm}^{2}$; pH:3 ; Time of deposition $30 \mathrm{~min}$

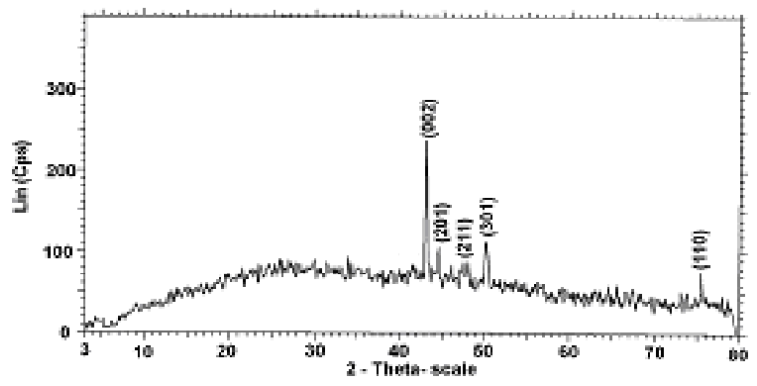

Fig. 2. XRD pattern of Electrodeposited CoMnP film; for Sample A1 Current Density $7 \mathrm{~mA} / \mathrm{cm}^{2}$; pH:3 Time of deposition $60 \mathrm{~min}$;

The XRD intensity data obtained was from $20^{\circ}$ to $80^{\circ}$. These data's are compared with Joint Committee for Powder Diffraction Data and the peaks were identified. CoMnP magnetic thin films exhibited (002),(201)and (110) plane primarily and has Hexagonal Close Packed (hcp) structure. (201) plane peaks has shifted because of the film stress for films obtained for sample A and Sample A1. From the previous studies [12], it is learnt that the film stress will shift $X$ Ray Difffractometer peak values. Debye - Scherrer formula $d=0.9 \lambda / \beta \operatorname{Cos} \theta$ in meters is used to calculate the crystalline sizes of the deposits. Where, $\beta=$ full width at half maximum (FWHM in radians), $\lambda$ is the wavelength of radiation. $\lambda=1.54056 \mathrm{~A}^{\circ} . \theta=$ position of the maximum diffraction. The values obtained clearly indicates that the crystalline sizes are in nanoscale. The shift of the plane peaks (002) and (201) were because of film stress for the sample A and Sample A1. Stress was low for both Sample A1 and Sample B1 which contains $2 \mathrm{gL}^{-1}$ of Benzene Sulfonic Acid. Magnetic thin film stress has increased on increasing the concentration of Benzene Sulfonic Acid to $4 \mathrm{gL}^{-1}$ in the baths of Sample A2 and of Sample B2. It is because of incorporation of decomposed products of the organic additive Benzene Sulfonic Acid in to the film.

Electrodeposited CoMnP films for all the bath compositions were subjected to Scanning Electron Microscopic studies. The monographs are shown in Fig. 3 to Fig. 5. Fig. 3 shows the SEM 
image of electrodeposited CoMnP thin film; Composition : Sample A2; ; Current Density: $5 \mathrm{mAcm}^{-2}$ Time of deposition: 60 Min; pH: 3. Fig. 4 shows the SEM image of electrodeposited CoMnP thin film; Composition : Sample B; Current Density: $3 \mathrm{mAcm}^{-2}$ :Time of deposition: $30 \mathrm{Min}$; $\mathrm{pH}$ : 3. Fig. 5 shows the SEM image of electrodeposited CoMnP thin film; Composition : Sample B1; Current Density: 7 $\mathrm{mAcm}^{-2}$ : Time of deposition: $60 \mathrm{Min} ; \mathrm{pH}$ : 3. The magnetic film with very low concentration of Benzene Sulfonic Acid appeared to have a crevice pattern as shown in the Fig.3. The thin film obtained from a bath contained $4 \mathrm{gL}^{-1}$ of Benzene Sulfonic Acid was cracked through substrate due to the stress of the film as shown in the Fig. 4. By and Large, the Micrograph of the CoMnP magnetic thin film is greatly influenced by the additive Benzene Sulfonic Acid and current density. Adhesion of the thin magnetic film with the substrate is tested by bend test and scratch test. It is found that these magnetic thin films holds a good adhesion with the substrate.

Electrodeposition studies are carried out for various bath compositions and for various bath conditions. The magnetic properties of these films were listed in Table 3 to 8 . The Current density, Time of deposition, Magnetic Saturation, Remanent and Coercivity were shown in table 3 to 8 . By and large, the magnetic properties of the film were found to increase with current density and duration of deposition. The effect of addition of Benzene Sulfonic Acid in to the baths (i.e., Sample A1,A2,B1and B2 ) along with $\mathrm{NaH}_{2} \mathrm{PO}_{2}$ was investigated. The magnetic properties of the thin film improve significantly upon adding low concentration the additive Benzene Sulfonic Acid. Under the best condition involving addition of $0.2 \mathrm{M}$ of $\mathrm{NaH}_{2} \mathrm{PO}_{2}$ and $4 \mathrm{gL}^{-1}$ of Benzene Sulfonic Acid at a current density of $7 \mathrm{~mA}-\mathrm{cm}^{-2}$ and time of deposition 60 minutes, the thickness of the film was found to be 3.5 micrometer with coercivity 1410 Oe and remanent $0.11 \mathrm{emu}$. Increase in magnetic properties of the films is mainly due to Benzene Sulfonic Acid. The electrodeposited thin magnetic CoMnP films were bright and uniform. The Benzene Sulfonic Acid molecules are found to have leveling effect, which ensures uniform orientation of crystals during the electrodeposition processes. On increasing the concentrartion of $\mathrm{NaH}_{2} \mathrm{PO}_{2}$ and Benzene Sulfonic Acid, the magnetic properties of the film decreased due to the stress present in the films. Stress is caused by the inclusion of decomposed products of the organic additive Benzene Sulfonic Acid.

TABLE III. MAGNETIC PROPERTIES OF ELECTRODEPOSITED COMNP THIN FILMS FOR SAMPLE A.

\begin{tabular}{lllll}
\hline $\begin{array}{l}\text { Current } \\
\text { density }\end{array}$ & $\begin{array}{l}\text { Time of } \\
\text { deposition }\end{array}$ & $\begin{array}{l}\text { Magnetic } \\
\text { saturation }\end{array}$ & Remanent & Coercivity \\
$\left(\mathrm{mA}-\mathrm{cm}^{-2}\right)$ & $(\mathrm{min})$ & $(\mathrm{emu})$ & $(\mathrm{emu})$ & $(\mathrm{Oe})$ \\
\hline 3 & 15 & 0.59 & 0.17 & 360 \\
3 & 30 & 0.57 & 0.20 & 460 \\
3 & 60 & 0.54 & 0.23 & 510 \\
5 & 15 & 0.53 & 0.27 & 660 \\
5 & 30 & 0.52 & 0.29 & 700 \\
5 & 60 & 0.50 & 0.31 & 760 \\
7 & 15 & 0.51 & 0.33 & 800 \\
7 & 30 & 0.47 & 0.34 & 860 \\
7 & 60 & 0.44 & 0.39 & 910 \\
\hline
\end{tabular}

TABLE IV MAGNETIC PROPERTIES OF ELECTRODEPOSITED COMNP THIN FILMS FOR SAMPLE AI.

\begin{tabular}{lllll}
\hline $\begin{array}{l}\text { Current } \\
\text { density }\end{array}$ & $\begin{array}{l}\text { Time of } \\
\text { deposition }\end{array}$ & $\begin{array}{l}\text { Magnetic } \\
\text { saturation }\end{array}$ & Remanent & Coercivity \\
$\left(\mathrm{mA}-\mathrm{cm}^{-2}\right)$ & $(\mathrm{min})$ & $(\mathrm{emu})$ & $(\mathrm{emu})$ & $(\mathrm{Oe})$ \\
\hline 3 & 15 & 0.60 & 0.01 & 560 \\
3 & 30 & 0.55 & 0.02 & 710 \\
3 & 60 & 0.51 & 0.03 & 760 \\
5 & 15 & 0.47 & 0.05 & 810 \\
5 & 30 & 0.40 & 0.07 & 860 \\
5 & 60 & 0.36 & 0.10 & 910 \\
7 & 15 & 0.32 & 0.11 & 920 \\
7 & 30 & 0.30 & 0.14 & 1110 \\
7 & 60 & 0.29 & 0.16 & 1210 \\
\hline
\end{tabular}

TABLE V. MAGNETIC PROPERTIES OF ELECTRODEPOSITED COMNP THIN FILMS FOR SAMPLE A2.

\begin{tabular}{lllll}
\hline $\begin{array}{l}\text { Current } \\
\text { density } \\
\left(\mathrm{mA}-\mathrm{cm}^{-2}\right)\end{array}$ & $\begin{array}{l}\text { Time of } \\
\text { deposition }\end{array}$ & $\begin{array}{l}\text { Magnetic } \\
\text { saturation }\end{array}$ & Remanent & Coercivity \\
\hline 3 & 15 & 0.36 & 0.01 & 610 \\
3 & 30 & 0.34 & 0.02 & 710 \\
3 & 60 & 0.33 & 0.03 & 810 \\
5 & 15 & 0.29 & 0.04 & 910 \\
5 & 30 & 0.26 & 0.05 & 1010 \\
5 & 60 & 0.25 & 0.07 & 1060 \\
7 & 15 & 0.19 & 0.08 & 1110 \\
7 & 30 & 0.17 & 0.09 & 1310 \\
7 & 60 & 0.15 & 0.11 & 1410 \\
\hline
\end{tabular}

TABLE VI MAGNETIC PROPERTIES OF ELECTRODEPOSITED COMNP THIN FILMS FOR SAMPLE B.

\begin{tabular}{lllll}
\hline $\begin{array}{l}\text { Current } \\
\text { density }\end{array}$ & $\begin{array}{l}\text { Time of } \\
\text { deposition }\end{array}$ & $\begin{array}{l}\text { Magnetic } \\
\text { saturation }\end{array}$ & Remanent & Coercivity \\
$\left(\mathrm{mA}-\mathrm{cm}^{-2}\right)$ & $(\mathrm{min})$ & $(\mathrm{emu})$ & $(\mathrm{emu})$ & $(\mathrm{Oe})$ \\
\hline 3 & 15 & 0.91 & 0.45 & 460 \\
3 & 30 & 0.89 & 0.48 & 560 \\
3 & 60 & 0.86 & 0.49 & 610 \\
5 & 15 & 0.83 & 0.49 & 660 \\
5 & 30 & 0.81 & 0.55 & 760 \\
5 & 60 & 0.79 & 0.58 & 785 \\
7 & 15 & 0.75 & 0.61 & 860 \\
7 & 30 & 0.73 & 0.64 & 910 \\
7 & 60 & 0.69 & 0.66 & 960 \\
\hline \multicolumn{4}{l}{ TABLE VII MAGNETIC PROPERTIES OF ELECTRODEPOSITED COMNP } \\
THIN FILMS FOR SAMPLE B1.
\end{tabular}

\begin{tabular}{|c|c|c|c|c|}
\hline $\begin{array}{l}\text { Current } \\
\text { density } \\
\left(\mathrm{mA}-\mathrm{cm}^{-2}\right)\end{array}$ & $\begin{array}{l}\text { Time of } \\
\text { deposition } \\
(\text { min })\end{array}$ & $\begin{array}{l}\text { Magnetic } \\
\text { saturation } \\
(\mathrm{emu})\end{array}$ & $\begin{array}{l}\text { Remanent } \\
\text { ( emu) }\end{array}$ & $\begin{array}{l}\text { Coercivity } \\
\text { ( Oe ) }\end{array}$ \\
\hline 3 & 15 & 0.85 & 0.12 & 710 \\
\hline 3 & 30 & 0.82 & 0.12 & 760 \\
\hline 3 & 60 & 0.77 & 0.13 & 810 \\
\hline 5 & 15 & 0.75 & 0.15 & 860 \\
\hline 5 & 30 & 0.70 & 0.16 & 960 \\
\hline 5 & 60 & 0.66 & 0.18 & 1010 \\
\hline 7 & 15 & 0.62 & 0.20 & 1110 \\
\hline 7 & 30 & 0.60 & 0.22 & 1210 \\
\hline 7 & 60 & 0.57 & 0.25 & 1310 \\
\hline
\end{tabular}

TABLE VIII MAGNETIC PROPERTIES OF ELECTRODEPOSITED COMNP THIN FILMS FOR SAMPLE $B 2$. 


\begin{tabular}{lllll}
\hline $\begin{array}{l}\text { Current } \\
\text { density }\end{array}$ & $\begin{array}{l}\text { Time of } \\
\text { deposition }\end{array}$ & $\begin{array}{l}\text { Magnetic } \\
\text { saturation }\end{array}$ & Remanent & Coercivity \\
$\left(\mathrm{mA}^{\left.-\mathrm{cm}^{-2}\right)}\right.$ & $(\mathrm{min})$ & $(\mathrm{emu})$ & $(\mathrm{emu})$ & $(\mathrm{Oe})$ \\
\hline 3 & 15 & 0.41 & 0.04 & 560 \\
3 & 30 & 0.40 & 0.05 & 610 \\
3 & 60 & 0.36 & 0.06 & 660 \\
5 & 15 & 0.34 & 0.08 & 710 \\
5 & 30 & 0.33 & 0.09 & 760 \\
5 & 60 & 0.32 & 0.11 & 785 \\
7 & 15 & 0.29 & 0.13 & 860 \\
7 & 30 & 0.30 & 0.15 & 960 \\
7 & 60 & 0.28 & 0.17 & 1060 \\
\hline
\end{tabular}

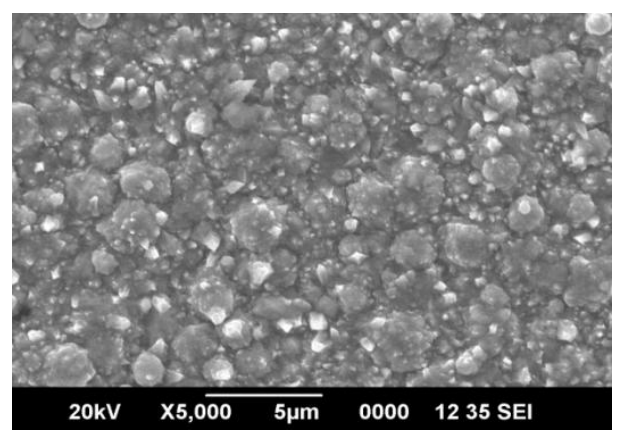

Fig. 3. SEM image of electrodeposited CoMnP film;Composition : sample three; Current Density: $5 \mathrm{mAcm}^{-2}$; Time of deposition: $60 \mathrm{Min} ; \mathrm{pH}: 3$

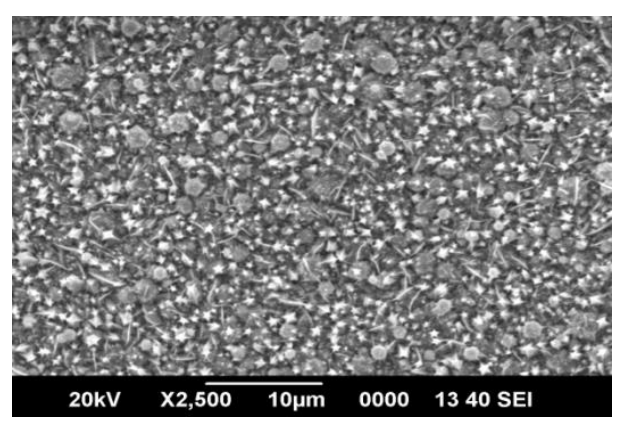

Fig.4.SEM image of electrodeposited CoMnP film;Composition : sample four; Current Density: $3 \mathrm{mAcm}^{-2}$; Time of deposition: $30 \mathrm{Min}$; $\mathrm{pH}: 3$

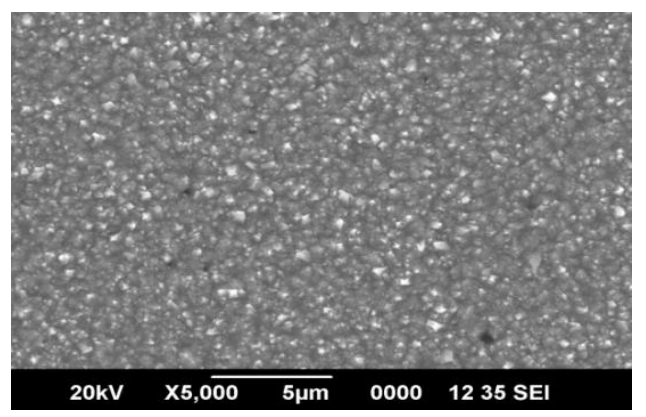

Fig. 5. SEM image of electrodeposited CoMnP film;Composition : sample five; Current Density: $7 \mathrm{mAcm}^{-2}$; Time of deposition: $60 \mathrm{Min} ; \mathrm{pH}: 3$

\section{CONCLUSION}

CoMnP magnetic thin films were successfully deposited by electrochemical deposition technique. Effect of deposition condition and Benzene Sulfonic Acid concentrations in the starting solution ( Sample A and Sample B ) on the formation of CoMnP thin films was investigated. The concentrations of the constituents in the solution A and B were optimized using a Hull cell method. CoMnP magnetic thin films had Hexagonal Close Packed
(HCP) structure and exhibited (002),(201) and (110) planes. Under the best condition involving addition of $0.2 \mathrm{M}$ of $\mathrm{NaH}_{2} \mathrm{PO}_{2}$ and $4 \mathrm{gL}^{-1}$ of Benzene Sulfonic Acid at a current density of $7 \mathrm{~mA}-\mathrm{cm}^{-2}$ and time of deposition 60 minutes, the thickness of the film was found to be 3.5 micrometer with coercivity 1410 Oe and remanent 0.12 emu. Stress was low for bath Sample A1 and Sample B1 which contains $2 \mathrm{gL}^{-1}$ of Benzene Sulfonic Acid. Stress has increased on increasing the concentration of Benzene Sulfonic Acid to $4 \mathrm{gL}^{-1}$ in the baths Sample A2 and Sample B2. It is because of incorporation of decomposed products of additive Benzene Sulfonic Acid in to the film.

\section{ACKNOWLEDGMENT}

The authors thank the management of Sri Ramakrishna Engineering College,Coimbatore and Kathir College of Engineering, Coimbatore for their support and kind permission to publish this paper.

\section{REFERENCES}

1. J. Branebjerg, P. Gravesen, "A new electrostatic actuator proving improved stroke length and force", Proc. IEEE Int. Workshop Micro Electro Mechanical Syst., pp. 6-11, 1992.

2. M. Koch, A. G. R. Evans, A. Brunnschweiler, "Dynamic micropump driven with a screen-printed PZT actuator", J. Micromech. Microeng., vol. 8, no. 2, pp. 119-122, Jun. 1998.

3. O. C. Jeong, S. S. Yang, " Fabrication and test of a thermopneumatic micropump with a corrugated $\mathrm{p} \backslash \$\{+\} \backslash \$$ diaghragm ", Sens. Actuators A Phys., vol. 83, no. 1, pp. 249-255, May 2000.

4. Y. Yang, Z. Zhou, X. Ye, X. Jiang, "A bimetallic thermally actuated micropump", Microelectromech. Syst. (MEMS) ASME, vol. DSC-59, pp 351-354, 1996

5. M. Khoo, C. Liu, "Micro magnetic silicone elastomer membrane actuator", Sens. Actuators A Phys., vol. 89, no. 3, pp. 259-266, Apr. 2001

6. C. R. Neagu, J. G. E. Gardeniers, M. Elwenspoek, J. J. Kelly, "An electrochemical microactuator: Principle and first results", J. Microelectromech. Syst., vol. 5, no. 1, pp. 2-9, Mar. 1996.

7. D. Xu, L. Wang, G. Ding, Y. Zhou, A. Yu, B. Cai, "Characteristics and fabrication of NiTi/Si diaphragm micropump", Sens. Actuators A Phys., vol. 93, no. 1, pp. 87-92, Aug. 2001.

8. L L Lee, D E Laughlin and D N Lambeth,' CrMn Underlayers for CoCrPt thin film media", IEEE Transactions on Magnetics. Vol. 34, pp 1561-1563, 1998

9. Sebastian Fahler, Ullrich Hannemann, SteffenOswald,Volker Neu,Bernhard Holzapfel, and Ludwig Schultz, "Corrosion of Highly Coercive, Highly. Textured. Nd-Fe-B Films", IEEE Transactions on Magnetics, Vol. 39, pp 2950- 2952, 2003.

10. Krishnappa.M.RM, Rajasekaran. N, Ganesan.S and Emerson.R.N, "Influence of organic additive thiourea on the properties of hard magnetic CoMnP thin film alloys electrodeposited form Chloride bath", Journal ofOptoelectronics andAdvanced Materials, Vol. 12, No. 9, pp.1863-1868, 2010.

11. Krishnappa.M.RM, Rajasekaran. N, Ganesan.S and Emerson.R.N, "Effect of current density on electrodeposited CoMnP thin films", Journal of Engineering and Applied Sciences, Vol. 5, No. 7, pp. 1-10, 2010.

12. Krishnappa.M.RM, Rajasekaran. N, Ganesan.S and Emerson.R.N, "Mechanical and magnetic properties of Electrodeposited CoMnP thin film alloys", Journal of Engineering and Applied Sciences, Vol. 6, No. 1, pp. 21-26, 2011

\section{AUTHORS PROFILE}

M.RM. Krishnappa Department of Physics Sri Ramakrishna Engineering College, Coimbatore, India.

K.V. Kannan Nithin Department of Physics Kathir College of Engineering, Coimbatore, India. 